\title{
EL ESTADO, LA ÉLITE Y LAS COMUNIDADES: LOS CONTRATOS EN TORNO A LA EXPLOTACIÓN DE LA MADREPERLA EN EL PACÍFICO DE COSTA RICA (SIGLOS XIX Y XX)
}

\author{
THE STATE, THE ELITE AND THE COMMUNITIES: THE CONTRACTS \\ AROUND THE EXPLOITATION OF THE MADREPERLA IN THE PACIFIC \\ OF COSTA RICA (XIX AND XX CENTURIES)
}

Elizet Payne Iglesias

Recibido: 18/10/2016 Aceptado: 17/01/2017

\section{Resumen}

Este estudio tiene como fin mostrar, a través del análisis de los contratos otorgados por el Estado para la explotación de la madreperla, los privilegios concedidos a la élite costarricense y a los inversionistas extranjeros, en detrimento de las formas tradicionales de manejo del recurso por parte de las comunidades costeras del Pacífico; estas reaccionaron en defensa de sus intereses patrimoniales utilizando diversos medios; entre ellos, la presión directa o indirecta, mediante la gestión de cartas dirigidas a las autoridades nacionales y locales.

Palabras clave: Pinctada mazatlanica; madreperla; perlas; concha nácar; Estado liberal; élites.

\begin{abstract}
This study seeks to show, by analyzing the contracts of the exploitation of mother of pearl granted by the state, the privileges granted to the Costa Rican elite and the foreign investors and, the loss of the traditional exploitation by the coastal communities, in particular Nicoya. These communities reacted in defense of their rights by using several means including direct pressure or by sending letters to the local and national authorities.
\end{abstract}

Keywords: Pinctada mazatlanica; mother of pearl; pearls; pearl shell; Liberal State; elite. 


\section{Introducción ${ }^{1}$}

Desde su llegada al Pacífico americano en 1513 y después de conocer y explotar los bancos perlíferos existentes en las costas e islas de Venezuela y Colombia en el mar Caribe, los españoles tenían informes de la existencia de las Islas de las Perlas en la actual Panamá. En Nicoya, hacia 1522, encontraron que el negocio de esta gema podría ser fructífero, de forma tal que la extracción generó las primeras redes de explotadores y comerciantes de perlas en manos de Gil González Dávila, Pedrarias Dávila y sus descendientes o el cronista Gonzalo Fernández de Oviedo, entre otros. A lo largo de la época colonial, comerciantes de la élite cartaginesa y nicaragüense, asentada en Granada y la villa de Nicaragua -hoy Rivas-, vendían las perlas en el golfo de Nicoya y en la costa pacífica de la península. Las gemas de mayor calidad eran comercializadas u obsequiadas a la corte y ricos personajes, o bien, llevadas como promesas a ciertas iglesias con el fin de engalanar a las vírgenes. La extracción en el golfo fue más limitada que en Panamá; no obstante, aún se recogían perlas en la década de los años 40 del siglo XX, en el golfo y se comercializaban a través de Puntarenas.

En el siglo XIX y en las primeras décadas del XX, bajo la insignia del progreso, en Costa Rica como en el resto de países centroamericanos y del Caribe, se comenzaron a concesionar los recursos naturales con el objetivo de fomentar las inversiones, generar nuevos ingresos al Estado y favorecer la creación de fuentes de trabajo. Esta puede considerarse como la época de las concesiones, las cuales se ejecutaban para la construcción de los ferrocarriles, la minería -de oro y plata-, las maderas preciosas y los recursos marinos y costeros. Muchos de estos, tuvieron gran demanda en los mercados internacionales. En lo que se refiere a los productos del mar-que son objeto de este análisis- la ostra de concha nácar era considerada un recurso muy valioso, pues de esta se aprovechaba tanto la perla (recurso más caro, pero más escaso en el medio) y el nácar, del cual se fabricaban botones y otros artículos de lujo.

La extracción y el comercio de perlas y madreperlas forma parte de la historia económica y social poco conocida en el país; no obstante, sí se conoce muy bien el papel que otros productos cumplieron como generadores de acumulación de capital, desde el final del periodo colonial y a lo largo del siglo XIX, tales como el tabaco, el café, el banano, el cacao, la minería de oro y el palo brasil.

Esta fue también por añadidura, la época de la presencia de gran cantidad de inversores nacionales y extranjeros, quienes actuaban en la mayoría de los casos en contubernio o alianza con el Estado y las élites locales y regionales. En este contexto, no cabe duda de que el espíritu liberal procuraba promover la riqueza privada, bajo el hombro protector del Estado y de los gobiernos del momento. También fue un periodo histórico en el que la población migrante del resto del istmo y de las islas del Caribe llegaba en busca de trabajo y de mejores condiciones de vida; así, en el Pacífico se 
contará con mano de obra migrante de origen nicaragüense, panameño, hondureño y salvadoreño, en particular.

En síntesis, el primer objetivo de este estudio es mostrar, a través del análisis de los contratos otorgados por el Estado, los privilegios concedidos a la élite costarricense y a los inversores extranjeros. En total serán analizados seis contratos firmados entre el Estado de Costa Rica y los empresarios privados, entre 1854 y 1923. Los contratos fueron cedidos con plazos diversos, lo cual se debía a la envergadura o poder del personaje beneficiado, o bien, a las posibilidades de extracción mayores o menores del recurso, como se analizará más adelante. Este último aspecto se relaciona con las pretensiones de rentabilidad, las ganancias en bruto y la especulación, debido a que estas empresas debían considerar el riesgo. Además, como toda actividad extractiva, era previsible el agotamiento del recurso marino tal como acaece en el presente caso.

Interesa también rescatar el papel de las comunidades costeras, sobre todo la posición asumida por los pescadores de perlas y los buzos de cabeza, quienes elevaron sus voces por la defensa de la extracción de su legendario y patrimonial recurso. En este sentido, se ha efectuado un gran esfuerzo para visibilizar a los pescadores, quienes no solo necesitaban de la pesca para sobrevivir, sino que eran contratados para extraer perlas y concha perla. Estas actividades con frecuencia estaban acompañadas por la explotación del tinte de caracol, recurso muy común extraído por las comunidades de Boruca, Nicoya, Punta Herradura y Bahía Culebra.

Varias investigaciones muestran los datos de exportación de la concha perla en el siglo XIX; por ejemplo, el trabajo del autor del primer libro de Historia de Costa Rica publicado por Felipe Molina en 1851 (Molina). Los viajeros Meagher, Wagner y Scherzer y Solano Astaburuaga, entre otros, también se refirieron a las actividades extractivas de perla y concha perla en el Pacífico costarricense (Wagner y Scherzer; Solano). Al mismo tiempo, otros ya hablaban del incentivo que constituiría para los empresarios la explotación de la concha perla (Martínez 156). Sin embargo, es de señalar que en realidad el país no se caracterizaría por sus actividades pesqueras; según Ana Cecilia Román, las labores extractivas producto de la pesca no representaban ni siquiera el uno por ciento de las exportaciones totales de la nación, entre 1883 y 1930 (Román 220).

Otro punto a estudiar se relaciona con los sitios bajo concesión y los materiales a explotar: las ostras o conchas de madreperla y su derivado más rentable: las perlas. La especie perlífera por excelencia se localiza en toda la faja pacífica del continente americano, desde Baja California hasta el Ecuador y se denomina Pinctada mazatlanica (Hanley, 1856). Este es el molusco, comúnmente llamado en la documentación como madreperla, concha nácar o concha-perla, del cual se extrae tanto la perla como el nácar de excelente calidad. 


\section{Los primeros contratos: Derechos y obligaciones}

Una buena cantidad de inversionistas extranjeros, entre ellos ingleses, alemanes, mexicanos y colombianos, incursionaron entre la élite nacional con el fin de lograr privilegios en actividades rentables; por ejemplo, la explotación de la concha nácar, aspecto que queda claro debido al análisis y a la composición de los contratistas y sus otorgantes.

A lo largo del periodo colonial, republicano y liberal, las élites controlaron los beneficios de dicha actividad (Payne, 2008; 2014). En el periodo federal, la primera compañía que solicitó permiso para la explotación de perlas en el Pacífico de Costa Rica lo hizo en 1825 y se llamó Compañia Nacional de Centroamérica para el fomento de la minería, pesca de perlas y comercio, cuyo presidente fue el guatemalteco Juan Bautista Irisarri. Este era ministro plenipotenciario en Chile y mantenía fuertes vínculos con capitalistas ingleses, miembros -según se expresa en el documento- del parlamento británico (ANCR. Federal, 545, 1825). Sin lugar a dudas, sus nexos con el comercio inglés, angloamericano, peruano, chileno y mexicano los heredó de su padre, Juan Bautista Irisarri, uno de los empresarios guatemaltecos más importantes de su época (Belaubre 2).

En una carta dirigida al gobierno de la República Federal Centroamericana, Irisarri solicitó permiso para establecer la compañía por acciones, con un capital inicial de 11000600 pesos disponibles, 400 de estos reservados para los ciudadanos de la República; con un valor de 500 pesos cada acción. Dicha solicitud fue respondida positivamente por el gobierno en la ciudad de Guatemala, a un año de constituirse la República Federal (ANCR. Federal, 545, 1825). La compañía bancaria representante de esta sociedad se llamó Lockburn y compañía. No obstante, se desconoce si la empresa inició sus trabajos en suelo costarricense; una prueba de ello es que, documentos posteriores que remiten a los antecedentes de esta actividad no mencionan a dicha empresa. Es sabido, sin embargo, que tenía intereses en la minería y su principal accionista propuso la creación de un banco en Guatemala.

\section{Contrato Mora Porras con la firma Bayer, Mosson y Cañas}

El primer contrato firmado durante el periodo republicano se dio bajo el gobierno de Juan Rafael Mora Porras, el 2 de junio de 1854 (ANCR. Congreso, 7505, 1854). Este se acordó entre la compañía Bayer, Mosson y Cañas, por parte de los empresarios, y Joaquín Bernardo Calvo, de parte del Estado, su ministro de Estado en el despacho del Interior; quien expresó la necesidad de que el tesoro público aumentara a través del incentivo de nuevas inversiones, y "deseando... alentar el espíritu de especulación y de empresa" (ANCR. Congreso, 7505, 1854).

En el mismo documento, el presidente Mora Porras confirmó la contrata de la siguiente forma: "El Excelentísimo Congreso Constitucional de la República de Costa Rica. Decreta: que se aprueban todos los artículos de la contrata". El contrato otorgado 
por el gobierno de Mora Porras en 1854 se adjudicó por el término de 10 años. Los socios fueron Luis Bayer, de la ciudad de Badem; Elías Mosson, súbdito prusiano y José María Cañas por Costa Rica (ANCR. Congreso, 7505, 1854). Los viajeros Wagner y Scherzer visitaron en 1854 la hacienda de Cañas, cuñado del presidente Mora Porras, llamada Lepanto; desde allí pudieron observar y visitar las áreas perlíferas cercanas a la isla de San Lucas (Wagner y Scherzer, 183-189).

Con este convenio inició un largo proceso de beneficio a las élites josefinas y extranjeras en el aprovechamiento de los recursos naturales del país. El Estado de Costa Rica procuró por todos los medios aumentar la renta pública a través del fomento de nuevas actividades lucrativas. Sin duda, el café, las maderas tintóreas, el oro y la exportación de concha perla contribuyeron a fomentar la riqueza estatal, a la vez que beneficiaron a empresarios privados, ligados a los funcionarios gubernamentales.

Los ingresos ofrecidos por la compañía serían de 12000 pesos anuales distribuidos de la siguiente forma: 6000 adelantados al dar inicio la empresa, 6000 cada 6 meses hasta que se concluyera el contrato. La firma tenía la obligación de dar inicio a su labor en el plazo de un año, a partir de la firma del contrato, el cual sería nulo si en el término de 18 meses no se hubiera comenzado la explotación, en cuyo caso, el gobierno quedaría en la libertad de otorgar a otra empresa o persona tal privilegio. También se podía anular cuando la compañía incumpliera con los pagos en las fechas estipuladas.

En el caso de la contrata de 1854, se estipulaba que si la empresa resultaba rentable, los accionistas podían solicitar una prórroga del arrendamiento, a los 8 años de haber comenzado a funcionar. Esta solicitud se debía hacer por 5 años más, siempre y cuando la compañía le entregara al gobierno 18000 pesos por cada año de los cinco de prórroga y por semestres anticipados (ANCR. Congreso, 7505, 1854).

Como se observa, este contrato se firmó con extranjeros que tuvieron como similares en el país, la red política y económica más importante del momento. El Estado se limitó a otorgar para beneficio privado el recurso de la madreperla. En este documento también se observan las sendas ganancias que se suponía daría la extracción. No obstante, las fuentes consultadas no brindan datos sobre los beneficios obtenidos por la mencionada empresa.

\section{Solicitudes de Mauricio Gernsthein, Rafael Zaldívar, Gregorio Gallardo y Próspero Fernández}

Entre las décadas de 1850 y 1880, numerosos comerciantes solicitaron permiso para explotar los bancos de madreperla. Por ejemplo, en 1853, el alemán Mauricio Gernsthein dirigió una carta al presidente Mora Porras en la que solicitaba la firma de un contrato de arrendamiento con el fin de exportar ostras cerca del golfo de Puntarenas (ANCR. Presidente, 9119, 1853). 
Existe escasa información sobre el devenir de este negocio, pero al parecer no logró cuajar debido a la existencia de intereses más poderosos, ligados al grupo del presidente Mora Porras. No obstante, llaman la atención los requisitos que propone el solicitante, pues el plazo era sumamente corto, probablemente porque, como inversor aislado, quería probar la rentabilidad de la extracción, por lo cual trabajaría como exportador de concha perla solo por el término de dos años.

Gernsthein no proponía dedicarse a la extracción en sí, sino que su labor consistiría en recibir las conchas en Puntarenas y desde ahí exportarlas. La actividad daría inicio -según lo planificaba el empresario- el 1. de enero de 1854, obligándose a pagar al Estado la suma de 100 pesos, aunque dejaba a su favor el "derecho de tanteo": si la actividad fracasaba, únicamente pagaría la mitad (ANCR. Presidencia, 9119, 1853). A pesar de la poca información, la respuesta del Estado fue positiva, aunque, no impidió que otras personas o empresas ejercieran la misma labor.

Otra solicitud fue la del cubano Rafael Zaldívar, quien pretendía en 1875 comenzar el nuevo negocio de la pesca de concha perla y extracción de tintas. Se desconoce si su petición fue aprobada, pero era bastante ambiciosa; además, se destaca que: a) el privilegio se le otorgara por 25 años, b) se permitiera la introducción de maquinaria y útiles necesarios libres de todo derecho, c) los productos o tinturas se conserven sin que se les imponga ningún derecho de exportación ni de consumo, d) los operarios extranjeros que ocupe la empresa fuesen exonerados del servicio militar, e) la empresa pudiera cortar y extraer la materia colorante de cualquier árbol de tinte en los montes y terrenos baldíos y f) quedará sin efecto la concesión si el empresario no diera inicio a los trabajos en el año 1876 (ANCR. Congreso, 8571, 1875).

En respuesta, la comisión permanente a la cual se le consultó, respondió lo siguiente:

No desconozco que la empresa de que se trata como muy bien lo ha dicho el mismo proponente, es no solo de utilidad particular para él, sino también de conveniencia jeneral, y en este sentido no vacilo en afirmar que debería concederse el privilegio solicitado más no mostrando entre las atribuciones que el artículo 94 de la Constitución señala a este alto cuerpo, la de conceder esta clase de privilegios; parece muy racional, reservar este asunto a la decisión del Soberano Congreso Nacional en su próxima reunión extraordinaria (ANCR. Congreso, 8571, 1875).

Un año después, otro negociante, Gregorio Gallardo, le solicitó al gobernador de Puntarenas habilitar la pesca de la madreperla con buzos de cabeza, debido a que no era ilegal, a pesar de que, como era sabido, el general Próspero Fernández tenía el privilegio exclusivo de esta actividad durante cinco años en todo el Pacífico de la República. Aunque Fernández no había iniciado los trabajos, el gobernador le envió la solicitud al presidente de la República, quien se negó a apoyar la petición de Gallardo (ANCR. Congreso, 8540, 1876). Este continuó quejándose del procedimiento 
para adjudicar los contratos de privilegio, pues argumentaba que pescaría con buzos de cabeza. Dicha petición fue aprobada con los siguientes argumentos:

Vuestra comisión de yndustria ha examinado con escrupuloso cuidado la proposición del general don Próspero Fernández por la que solicita el privilegio por cinco años para explotar la riqueza natural de nuestras costas del Pacífico, dando con esto un nuevo manantial para el fomento de nuestro comercio y abriendo a nuestro [enmendado: comercio] mercado un nuevo motor de su prosperidad (ANCR. Congreso, 8540, 1876).

A raíz de tales deliberaciones, el Congreso decretó:

Artículo 1. Concédase al expresado señor general don Próspero Fernández, el privilegio exclusivo por el término de cinco años, para explotar la pesca de concha de perla en el litoral del océano Pacifico correspondiente al dominio de la República (ANCR. Congreso, 8540, 1876).

El general indicó que pagaría 2000 pesos al Estado en la forma que se determinara y debería cancelar el monto al finalizar el primer año de la explotación, desde que esta actividad diera comienzo. Quedaba además con el privilegio de traspasar el derecho, siempre y cuando tuviese la autorización del Gobierno. A pesar de haber nacido con tantos privilegios a su favor, la empresa de Fernández tuvo escasos resultados económicos y el contrato en cuestión fue anulado en 1881.

\section{Un contrato muy ambicioso y poco rentable, el de Demetrio Yglesias y Llorente}

En 1885, bajo la presidencia del liberal Bernardo Soto y sellado por su ministro de Fomento, el Dr. Carlos Durán, se le otorgó el privilegio a Demetrio Yglesias y Llorente, miembro de una prominente familia josefina, emparentado por matrimonio con una Castro Fernández y padre de quien sería años después el presidente, Rafael Yglesias Castro (ANCR. Gobernación, 7145, 1885).

El Gobierno dio en arrendamiento a Demetrio Yglesias y Llorente, por el término de "diez y seis años, los placeres o yacimientos de concha perla en todo el litoral de la costa, golfos e islas del Pacífico". Yglesias se comprometió a pagarle al Gobierno durante los primeros 6 años, 1000 pesos anuales y 2000 por los 10 años restantes. Reconocería, además, 6 pesos por cada 1000 kilogramos de concha perla extraída en los primeros 6 años y 8 pesos por cada 1000 kilogramos en los 10 años subsiguientes (ANCR. Gobernación, 7145, 1885).

La compañía sería considerada costarricense, aunque alguno de los socios fuera extranjero y por lo tanto, quedaban sujetos a los Tribunales de Justicia de la República y no deberían alegar nunca derechos de extranjería, por lo tanto, no habría injerencia alguna de diplomáticos extranjeros (ANCR. Gobernación, 7145, 1885). 
Sumado a esto, la compañía de Yglesias no podía ser traspasada, cedida, enajenada o hipotecada sin notificación al Gobierno. Menos aún, cuando esta hubiera celebrado un acuerdo con algún gobierno extranjero; en ese caso la compañía perdería el contrato, las embarcaciones que tuviera y los demás útiles y enseres. A diferencia de los contratos anteriores, el de Yglesias y Llorente fue más complejo en sus requisitos y más cuidadoso en relación con los supuestos reclamos de alguna potencia extranjera; en este caso, el Estado ponía regulaciones con respecto a los posibles socios extranjeros y mostraba su celo con respecto al contrabando de concha perla, de esta forma:

La compañia se compromete de la manera más terminante a vigilar y cuidar el contrabando y antes bien ofrece su cooperación al gobierno para impedirlo en la costa, facilitándole sus embarcaciones y demás auxilios cuando fuere necesario (ANCR. Gobernación, 7145, 1885).

En este, las autoridades estaban autorizadas a visitar las embarcaciones siempre que tuvieran motivos para sospechar que se estuviera cometiendo algún fraude.

Como cualquier contrato relacionado con la cesión de terrenos y de recursos estatales, este incorporaba lo referente a la explotación de otros recursos, así como la posibilidad de adquirir, por denuncia o compra, los terrenos baldíos cercanos a la costa, los cuales se pudieran necesitar para el ensanche de su empresa. También podía ocupar porciones de la milla libre, ya sea para construir edificios, formar estanques, hacer potreros, sembrar granos u otras plantaciones útiles, sin adquirir en esos casos, la propiedad del terreno ocupado (ANCR. Gobernación, 7145, 1885).

El contrato era más específico con respecto a la introducción libre de derechos de cualesquiera impuestos y cargas, buques de vapor y vela, máquinas, aparatos, vestidos y todo lo necesario para la operación del buceo. Además, se autorizada a dicha empresa para importar materiales y granos destinados para la alimentación, con la condición de que estos fueran para el uso de empleados y operarios.

Yglesias y Llorente se comprometía a entregar al Gobierno 20000 pesos efectivos a los 4 meses de haber iniciado las operaciones de pesquería. Sobre esta suma el interés era del seis por ciento anual e iría en aumento por las cantidades correspondientes a las anualidades fijas, como por la parte proporcional de la concha extraída (ANCR. Gobernación, 7145, 1885).

Además, se obligaba a que, al finalizar el contrato, el arrendamiento quedaría a beneficio de la nación, lo mismo que las mejoras hechas en los criaderos o placeres, así como en los edificios y construcciones existentes en los terrenos de la milla marítima. Mientras que las embarcaciones, máquinas, enseres y útiles quedarían como propiedad de los empresarios (ANCR. Gobernación, 7145, 1885). El contrato fue derogado el 29 de julio de 1886, pues no estaba en armonía con las nuevas disposiciones fiscales; no obstante, hubo otra licitación que apareció en La Gaceta del 17 de agosto de 1886 de la cual se desconoce su destino (ANCR. Gobernación, 7145, 1885). 


\section{Contrato Hidalgo}

A dos años del contrato con Demetrio Yglesias y Llorente, un empresario mexicano, Pablo Hidalgo (representado por su hermano residente en Costa Rica), solicitó permiso para extraer concha perla en el Pacífico del país por el término de 20 años, el cual fue concedido (ANCR. Fomento, 967, 1887). La petición la efectuó Pablo Hidalgo Navarro, mexicano en representación de la casa Hidalgo Carreaga y Compañia, con un depósito de 7100 pesos. El contrato es parecido al anterior, pero en este caso, se comprometía a pagar 350 pesos de arriendo al año y 9 pesos por cada 1000 kilos de concha para exportar. Este contrato generó muchas controversias entre los pobladores de Puntarenas y del Golfo Dulce, aspecto que se analizará en la última sección de este trabajo.

\section{Contrato Tinoco y Cruz}

Otro contrato que inmiscuyó a la élite nacional fue el otorgado en 1919 a Guillermo Tinoco Gutiérrez, primo hermano de Federico y Joaquín Tinoco Granados. Guillermo, además, estaba casado con una hija del Dr. Carlos Durán, personaje muy importante en el ámbito nacional; y su socio era otro conocido empresario Hermenegildo Cruz (ANCR. Congreso, 11440, 1919).

En el contrato firmado por Tinoco y Cruz con el Estado, se les concedía la explotación de la costa entre la península de Herradura y la de Santa Elena. Dicho permiso les dio a los contratistas el derecho exclusivo de fabricar a gran escala, la libertad de importación, por una sola vez, de la maquinaria y materiales necesarios, bajo la supervisión del Gobierno y sobre el pedido para su correspondiente exención (ANCR. Congreso, 11440, 1919).

Por su lado, el:

Contratista se obligaba a pagar al Tesoro Público como precio de esta concesión, el cinco por ciento de la riqueza que exporte, derecho que cubrirá en la forma corriente de impuestos de exportación y en la misma forma que este tributo se calcula. A excepción de ese tributo, la empresa no será gravada con impuestos directos nacionales ni municipales, ni pagará otra contribución que las indirectas que hoy rigen (ANCR. Congreso, 11440, 1919). ${ }^{2}$

El contrato tampoco permitía el traspaso de la concesión a un tercero, sin el previo permiso del Poder Ejecutivo. En caso de que fuera negociado con un extranjero, no se llevaría a la vía diplomática, aspecto incorporado ya en el contrato ofrecido a Demetrio Yglesias y Llorente en 1885.

Los empresarios también deberían instalar una fábrica de botones de concha nácar con toda su maquinaria, trabajos y diseños necesarios, en el término de un año. También deberían abastecer la demanda nacional y a la vez, podrían exportar, de lo cual debían informar siempre al Gobierno. Además, se obligaban a ocupar 
mano de obra nacional e instruirles en el oficio. Finalmente, se estableció como sede de la empresa extractora el puerto de Puntarenas (ANCR. Fomento, 5658, 1919).

El contrato Tinoco-Cruz comprendía un periodo bastante amplio, se adjudicó por el término de 20 años, pero el Poder Ejecutivo podría declararlo caduco por falta de cumplimiento de los contratistas a cualesquiera de las obligaciones aquí estipuladas (ANCR. Congreso, 11440, 1919). Además, resulta importante agregar que la actividad exportadora de concha perla había decaído bastante para esa época, debido al agotamiento de los bancos y a la baja en la demanda internacional.

Cuando los Tinoco cayeron en desgracia debido al derrocamiento de su régimen de facto, el contrato otorgado a Guillermo Tinoco Gutiérrez fue muy cuestionado por los pobladores dedicados a la extracción de concha perla y por otros empresarios del área de Puntarenas. En abril de 1919, en un telegrama firmado por Guillermo Tinoco dirigido al ministro de Gobernación, este le consultaba acerca de las razones por las que se le había negado a su socio, el señor Cruz, a pescar concha perla (ANCR. Gobernación, 428, 1919).

La respuesta del ministro fue que no existía tal prohibición, aunque sí estaba vedada la pesca con maquinaria. Tinoco continuó reclamando sus derechos firmados en el contrato, por lo cual, en octubre de 1919 -cuando ya había caído el régimen de su primo- hubo otra solicitud de pesca de Darío Espinoza y Jesús Guillén, a quienes el jefe del resguardo del Coco les vedó la pesca de concha nácar, bajo el argumento del secretario de Gobernación y Policía negaba el permiso, en virtud del contrato otorgado a Guillermo Tinoco (ANCR. Gobernación, 428, 1919). Guillermo Tinoco tenía una propiedad en la actual playa Sámara.

Sin duda, este contrato estuvo implicado en controversias, posiblemente de parte de quienes habían adversado al régimen y aumentaron aún más, desde el momento de la caída de la breve dictadura. Otro reclamo se dio en octubre de 1919, cuando don Enrique Mac Adam pidió licencia ante el gobernador de Puntarenas para pescar madreperla. Acerca de otorgar permiso al señor Mac Adam de pescar con maquinaria, como lo hacía Hermenegildo Cruz en virtud del contrato con Guillermo Tinoco (ANCR. Gobernación, 428, 1919); la respuesta del ministro fue tajante: "Por el momento no conviene otorgar dichos permisos".

La concesión Tinoco-Cruz fue revisada en 1920, a raíz de otra solicitud de pesca de concha nácar (ANCR. Fomento, 10332, 1920). Se refiere a una petición enviada por el señor Santiago Sagel, la cual no fue concedida, pues encontraron que el contrato mencionado seguía vigente, lo cual impedía que se le otorgase a otra persona o firma comercial. Conforme pasaron los días, dicho contrato entró en tal controversia que al socio Hermenegildo Cruz y otro comerciante, Manuel Pinel, les fueron denegados los permisos (ANCR. Fomento, 10332, 1920). ${ }^{3}$ La crisis fue tal, que abundaron las 
solicitudes de permisos. Entre estas, las de los señores Casimiro y Darío Espinoza Méndez y Jesús Guillén para pescar por buceo de cabeza desde Punta Guiones hasta Santa Elena (ANCR. Fomento, 10332, 1920).

En 1920, los vecinos de Puntarenas pidieron declarar nulo el contrato celebrado entre el gobierno de Federico Tinoco y Guillermo Tinoco y su socio, para la explotación de concha perla, alegando que las ganancias derivadas serían redistribuidas entre las comunidades:

Y para que se siga explotando dicho negocio mediante un impuesto que será distribuido entre las municipalidades, hospitales y casas de beneficencia de las provincias de Puntarenas y Guanacaste (ANCR. Congreso, 11741, 1920).

\section{Contrato Abouhamad}

El último contrato otorgado en estas condiciones se firmó en 1923 durante el gobierno de Julio Acosta, a favor del ciudadano establecido en París B. Abouhamad, representado en Costa Rica por Jorge Aguilar Morúa (ANCR. Congreso, 13069, 1923). Este se otorgó por 10 años, prorrogables a 15, en las zonas perlíferas entre Morro Hermoso a Santa Elena y de Punta Dominical a Punta Burica. ${ }^{4}$ Se separaron los sitios con el fin de explotar por partes los placeres de las ostras. Los contratistas tendrían el derecho a pescar en la primera sección durante el primer semestre de cada año y en la segunda sección, durante el segundo semestre en cada año de contrato. Y se concedió dicho documento, sin perjuicio de los derechos adquiridos por terceros.

Los inversores firmantes debían pagar al Gobierno el 15 por ciento sobre el producto de la exportación o de la comercialización del artículo en el país, al hacer el corte de ventas semestralmente, pagaderos en colones del curso corriente. La mitad de los ingresos se entregaría a la municipalidad de Liberia para repartirlo entre los cantones de Guanacaste, y la otra mitad se dividiría en partes iguales entre las municipalidades de Puntarenas y Esparta (ANCR. Congreso, 13069, 1923).

En 1923, la Comisión de Fomento del Congreso Constitucional señaló como de "mucho interés nacional" la contratación celebrada entre el secretario de Fomento y Jorge Aguilar Morúa, como representante de los señores S. y B. Abouhamad, sobre el arriendo de zonas perlíferas en la costa del Pacífico. El argumento para aprobar dicha contrata indicaba que:

Por tratarse de un negocio poco conocido entre nosotros y acerca del cual sinceramente confesamos nuestro personal desconocimiento, hemos debido acudir al consejo de personas peritas en la materia (ANCR. Congreso, 13069, 1923). 
Por parte del Estado se recurrió al señor Juan Romagosa, quien fue señalado como un buen conocedor del tema. Este contrato no tuvo mayor impacto ya que terminó a los 6 meses; el contratista pidió una prórroga de dos años y se fue del país. Lo beneficioso a nivel histórico, es que el señor Romagosa efectuó un estudio de todos los contratos de esta índole otorgados con anterioridad. A raíz de esto, se procedió a redactar un breve historial de la situación de los contratos previos, lo cual permitió conocer los contratos de Demetrio Yglesias y Llorente y Tinoco-Cruz. La comisión se pronunció entonces contraria al trato con Abouhamad en 1923, con los siguientes argumentos:

Es un privilegio y todo privilegio es odioso. No es justo para los intereses del Estado no acatar una inteligente reglamentación. Tampoco es justo que una compañía extranjera venga a perseguir a nuestras gentes pobres del litoral que en gran parte viven de la industria de la concha perla (ANCR. Congreso, 13069, 1923. Negritas añadidas).

Se sumaba otro problema que estaba relacionado con el riesgo de perjudicar la fábrica de botones fundada en Cartago, que requería de la concha perla como materia prima, pues al exportar la concha, este producto se vendería en el país a precios prohibitivos; según lo expresaron los miembros de la comisión contraria al contrato en cuestión ${ }^{5}$ (ANCR. Congreso, 13069, 1923). Se proponía que el desarrollo de una industria nacional podría convertir a Costa Rica en abastecedor de Centroamérica en el ramo de botones.

Para argumentar mejor las opiniones contrarias a la contrata con Abouhamad, se agregó una carta de los empresarios Enrique Runnebaum Benavides ${ }^{6}$ y Pantaleón Gómez Álvarez, en la que señalaban que:

La aprobación de ese contrato... lesionaría intereses creados o derechos adquiridos de terceros, en especial de aquellas personas quienes, amparadas en la ley promulgada en mil novecientos dos, que declara libre la pesca y exportación de la concha, se dedican a explotar ese negocio en la medida de sus capacidades y recursos, exponiéndose a los peligros que amenazan constantemente su vida y a los riesgos a que están sujetos los capitales invertidos en la difícil y peligrosa industria (ANCR. Congreso, 13069, 1923).

También, los comerciantes y pescadores de Puntarenas se manifestaron en contra, señalaban a este contrato como un monopolio "odioso", del cual el Estado no recibiría ningún beneficio. Se apoyaron en la ley de 1902, que había permitido la libre pesca, de manera que -decían-habían unos 500 buzos de cabeza viviendo de ese trabajo, y argumentaban: "Somos de opinión de que esa industria debe permanecer libre para su explotación, al amparo de las leyes existentes" (ANCR. Congreso, 13069, 1923).

Para finalizar dicho contrato, en 1931 el gobierno recibió una carta, fechada en Caracas y firmada por Salim Abouhamed, en la que pedía la devolución de 
40000 colones en bonos del Estado por incumplimiento de contrato por parte del gobierno de Costa Rica (ANCR. Congreso, 13069, 1923).

\section{Solicitudes para la explotación de conchas y otros recursos en el Pacífico}

Aun con todos sus riesgos, la extracción de concha nácar fue provechosa para varios capitalistas del Valle Central que diversificaron sus inversiones. De esta manera, la explotación de los productos derivados del mar se volvió muy lucrativa; se tenían noticias de cómo el guano se exportaba en grandes cantidades como abono, desde las costas pacíficas de Suramérica hacia Europa, así como la concha perla que se enviaba de los países asiáticos, Panamá, México y la propia Costa Rica.

En el contexto anterior, fue localizado un interesante documento de 1931, a nombre de la Sociedad Bancaria e Industrial de Cooperación Femenina, ${ }^{7}$ compuesta por Emilia Calvo Ramírez viuda de Pérez Zeledón, María Luján Mata de Goyenaga, Marina Rodríguez Arguedas, Leonor Espinach de Gutiérrez, consignadas como directoras de la mencionada Sociedad, en el que pedían permiso para aprovechar el recurso de las conchas marinas existentes en el Pacífico (ANCR, Congreso, 16064, 1931):

Empeñada nuestra Sociedad en aportar cuanto encuentre para mejorar su suerte económica, busca fuentes de riqueza nacionales y de ahorro, de donde pueda deducir algún provecho... Nuestro país abunda en riquezas naturales que están sin explotar esperando el capital que llegue a mover esas fuerzas y convertirlas en elementos de progreso y de comodidad, aumentando así el acervo común y contribuyendo a dar holgura y dicha. Es por eso que solicitamos de ese Alto Cuerpo, el derecho exclusivo por veinte años, para explotar en nombre de la Asociación a que ya hemos hecho referencia, todos los bancos naturales de concha, muertos, de cualquier clase que ellos sean y que se encuentran formando grandes bancos en los litorales del golfo de Nicoya y de la provincia de Guanacaste, para aplicarlos como fertilizantes de nuestras tierras o como materia prima para cualquier otra industria; asimismo los depósitos formados por la acción del tiempo con los excrementos o guanos de las aves marinas, localizados en las distintas islas del golfo de Nicoya, para ser empleados como guanos agrícolas; también en la explotación de la cal existente en el cerro denominado Isla del Toro. Tales riquezas se desperdician actualmente sin provecho alguno (ANCR, Congreso, 16064, 1931).

De acuerdo con los contratos otorgados anteriormente, pedían la libre introducción de la maquinaria adecuada para reducir a polvo los fertilizantes a explotar y los sacos para exportar. Claramente la asociación tenía un afán a favor de la incursión de las mujeres en la escena económica del país, por lo que recurren al discurso de la equidad:

Consideramos que al solicitar lo anterior nos mueve un sentimiento de justicia y equidad, al tratar de mejorar la suerte de la mujer costarricense ayudándola con el nacimiento de esta nueva industria nacional (ANCR, Congreso, 16064, 1931). ${ }^{8}$ 
En el estado actual de la investigación, se desconoce el futuro de tan interesante Asociación, aunque se pretendió obtener más información pero no fue posible.

En respuesta, el Congreso Constitucional de Costa Rica decretó:

Otórguese a la Sociedad Bancaria e Industrial de Cooperación Femenina, el derecho exclusivo para explotar por veinte años los bancos de concha, muertos, que se encuentran en la península de Nicoya y en general en las playas del Pacífico (ANCR, Congreso, 16064, 1931).

También se les concedió la facultad de explotar los bancos de guano, existentes en el cerro Isla del Toro, situado en el golfo de Nicoya (ANCR, Congreso, 16064, 1931). La sociedad se comprometía a vender al Departamento Nacional de Agricultura un 25 por ciento de la producción al precio de costo, e invertir un 2 por ciento para el establecimiento de una Escuela Agrícola en el Pacífico. Así mismo, el gobierno le concedió la exención de derechos de importación de maquinarias y demás instrumentos e implementos que la industria requiriera.

\section{El caso de la fábrica de botones de Enrique Runnebaum Benavides}

Como ha sido mencionado en el apartado sobre el contrato Abouhamad, la instalación de una fábrica de botones de concha nácar en Cartago, produjo el incremento de la demanda interna de ese material; no obstante, los beneficios dados a la exportación y, sobre todo, a la libertad de impuestos que gozaban los empresarios del ramo, afectaba a la industria local. En 1933 y en el contexto de la crisis económica mundial, la fábrica de botones marcaba cifras mínimas. El dueño de la empresa, Enrique Runnebaum Benavides, informó que "tenía parada" su fábrica de botones por el hecho de no poder competir con el producto extranjero, especialmente con el de Japón. Sostenía que no se podía competir con los japoneses por muchas razones; entre ellas, porque el jornal de las mujeres en Japón era muy bajo, en ese país se usaba maquinaria automática que no requería de tanta mano de obra y, finalmente, la obtención de la concha era sumamente fácil. Ante esto, sostenía que:

En cambio mi planta es manual y en ella puedo producir hasta un cincuenta por ciento más de botones, que los que se pueden consumir en todo el país, pero debido al precio tan ridículo a que se vende el botón japonés y al derecho de aduana tan poco que aquí se paga, el artículo, tomando en cuenta los muchos miles de botones que entran en un kilo de peso no me es posible poder trabajar porque me deja pérdida. Yo tengo que comprar la concha en Puntarenas, pagar acarreos a la estación del Ferrocarril al Pacífico, pagar fletes de ferrocarril, y una vez en San José, también tengo que pagar fletes de ahi a Cartago, los jornales que yo pago aquí son más altos que los que pagan los japoneses (ANCR. Congreso, 16706, 1933).

Todo indica que el Estado no apoyó ni estimuló totalmente al propietario local, posiblemente por el hecho de que las actividades de exportación de concha nácar 
producían beneficios a la élite nacional y, probablemente, porque los comerciantes importadores de botones no veían perjuicio en la adquisición de este producto en el extranjero, el cual entraba muy barato al mercado nacional. Runnebaum pedía que se aumentara el aforo a los botones importados de Japón, de 8 a 20 (ANCR. Congreso, 16706, 1933).

Las autoridades llevaron el caso a consulta en la Contaduría Mayor del Estado y esta respondió al respecto:

La Contaduría Mayor, ha sostenido la tesis de que la protección arancelaria debe otorgarse, de preferencia a las industrias nacionales cuya materia prima produce el país y las últimas leyes proteccionistas responden, en general, a esta doctrina (ANCR. Congreso, 16706, 1933).

La respuesta de la Contaduría Mayor es que al año se importaban unos 1000 kilos de botones, y eran tan baratos que 1000 gruesas de botones puestas en Puntarenas valían unos 25,00 dólares. Pero a pesar de los datos, la partida fijaba el arancel en 8,00 colones por kilogramo y se elevaba a 9,63 colones por kilo bruto, lo cual no podía considerarse muy barato, pues el botón que entraba al país era el de precio más bajo, pues se utilizaba en la fabricación de ropa a gran escala (ANCR. Congreso, 16706, 1933).

Finalmente, no se aprobó la solicitud de elevar el aforo a 20 colones con el argumento de que:

Elevando el aforo del botón de concha, finalmente corremos el riesgo casi seguro, de hacer de un aforo proteccionista, un aforo netamente fiscal, por lo incierto del negocio y la poca garantía que presta (ANCR. Congreso, 16706, 1933).

A pesar de ello, Runnebaum indicaba que:

Los botones que yo produzco son iguales a los que se importan del extranjero, en tamaños, calidad de concha y pulimento, ya que son hechos exactamente iguales en su procedimiento (ANCR. Congreso, 16706, 1933).

Lo anterior fue afirmado por el propio Congreso Nacional, pues las muestras de botones de concha enviadas al Congreso por el señor Runnebaum, probaban que el artículo producido en el país era superior y que en cuanto a la calidad podía, con ventaja, competir con el extranjero (ANCR. Congreso, 16706, 1933).

La respuesta fue contraria para el empresario, por lo que solicitó la revisión del aforo. Debido a la negativa del gobierno, Runnebaum le pidió al Estado que le comprara la fábrica, con el fin de trasladarla a la isla San Lucas, en donde se les enseñaría a los presos a producir botones. Ya en el gobierno de Cleto González Víquez le habían ofrecido 7000 colones, lo cual no aceptó, porque él había pagado 12000 colones 
por la maquinaria en cuestión. La fábrica terminó cerrando y el inversionista se orientó al ramo de la fabricación de bebidas (ANCR. Congreso, 16706, 1933).

\section{El Estado, la renta pública y persecución del contrabando}

A raíz de los contratos, el Estado se vio en la necesidad de legislar con el fin de interceder y limitar los excesos que se cometían. Esto no solo consistía en la penalización del contrabando, sino de los desacuerdos entre empresarios y Estado, el establecimiento de rentas e impuestos, así como la limitación de los abusos cometidos. Fue por fin en el año 1902 cuando se sentaron las bases para dicha legitimación con la Ley y Reglamento de bucerías, firmada en julio y agosto. Más tarde, en 1923, al efectuar una revisión de los contratos y las leyes existentes sobre el tema, el señor Romagosa, expresó:

Esa reglamentación fue un gran paso dado en el arreglo de un problema poco conocido para nuestros hombres de Estado; fue muy atinada y es digna de toda mi alabanza. Era ministro en ese tiempo don Manuel de Jesús Jiménez y acaso a sus reconocidas capacidades de estadista se deba la redacción de esa Ley (ANCR. Congreso, 13069, 1923).

Puede afirmarse que a partir de 1902, el Estado intervino de manera más coherente como mediador en la explotación de concha nácar. Esto podría deberse a una mejor organización del Gobierno, así como al incremento de la renta pública. Como se señaló arriba, la intervención estatal tenía que ver no solo con los impuestos, la persecución del contrabando, la restricción de los abusos de parte de los empresarios y el control de las fechas para la presentación de las solicitudes; sino que el Estado también respondió al precisar las áreas a explotar e imponer vedas, especialmente en el golfo de Nicoya (ANCR. Juzgado Contencioso Administrativo, 5941, 1892).

Aunque los datos sobre los ingresos a favor de las municipalidades no abundan, se han localizado los correspondientes a 1924, 1925 y 1926. Puede apreciarse la distribución de las entradas por municipalidad; en 1924, el municipio de Puntarenas calculó el ingreso total en 4200 colones que se repartían de la siguiente forma: Liberia un 50 por ciento, Esparta 25 por ciento y Puntarenas 25 por ciento. Los ingresos reales fueron escasos tal y como se indican: para Liberia 1575 colones, para Esparta 787,50 colones y para Puntarenas 787,50 colones. Como se observa, la municipalidad de Liberia fue la más beneficiada por la pesca de madre perlas, lo cual podría indicar que la actividad se incrementó en el Pacífico Norte del país -aumentando la presión sobre el recurso- y cedió frente a los agotados bancos perlíferos de las islas del golfo de Nicoya.

El contrato denominado Abrumar, de 1927, indica que los 5000 pesos se distribuyeron entre los 8 cantones de Guanacaste y los 4 de Puntarenas, obteniendo un total de 116.75 (ANCR. Congreso, 14674, 1927). En 1931, la exportación de concha 
perla alcanzó los 136652 kilogramos, con un valor de 35087 colones y en 1932 fue de 76437 kilos con un valor de 16490 colones.

En relación con la explotación excesiva de concha, ya en 1907, conforme la actividad extractiva entraba en crisis, se presentó un "Proyecto del Poder Ejecutivo, relativo a suspender por diez años, el derecho establecido por el 3 de julio de 1902, sobre la exportación de concha perla" (ANCR. Congreso, 10100, 1908). Este se suscribió de acuerdo con una solicitud de la municipalidad de Puntarenas, en la que suplicaba al Poder Ejecutivo la supresión del derecho de exportación de la concha perla a 2 céntimos el kilogramo. El acuerdo lo fundamentaban con el argumento de que existía en bodega una gran cantidad de concha perla que no había sido exportada, debido a la depreciación del artículo en los mercados internacionales, al punto de que apenas cubría el flete de mar.

Frente a esta situación, se adhirieron a la petición las municipalidades de Liberia, Nicoya, Santa Cruz, Carrillo, Cañas, Bagaces y Esparta. Liberia consideró, sin embargo, que la municipalidad que se beneficiaría sería la de Puntarenas, por lo que aprobó el acuerdo siempre y cuando se redujera el impuesto a la mitad. Ante la crisis y de acuerdo con la solicitud de los gobiernos locales mencionados, el Congreso de la República decretó: "Artículo único: Durante cinco años, contados desde la publicación del presente decreto, no se cobrará el impuesto establecido por ley de 3 de julio de 1902, sobre la exportación de concha perla" (ANCR. Congreso, 10100, 1908).

Después del contrato con Abouhamad, el Estado mostró su preocupación por fortalecer las leyes respecto a la pesca y la extracción de los recursos marinos y otros productos situados cerca de la costa. A raíz de ello, se aplicó un reglamento en 1924, denominado Reglamento de pesca de madreperla, firmado por el presidente Ricardo Jiménez y el secretario del despacho de Hacienda, Tomás Soley Güell (ANCR. Congreso, 13343, 1924). De acuerdo con esto, se determinó que el Estado, como controlador de los recursos a través de la Secretaría de Hacienda, sacaría periódicamente a subasta pública el derecho de pesca de la madreperla en el Pacífico del país. Para ello, se dio la atribución de dividir la costa en tres secciones: "con el fin de turnar la pesquería y conservar así la riqueza de los yacimientos" (ANCR. Congreso, 13343, 1924).

Pocos años después, en 1927, se emitió una Ley que declaraba la pesca libre de tortuga y concha perla (ANCR. La Gaceta, 133, 1927). Esta ley sostenía, como argumento, que la liberación de los permisos y, sobre todo, de los contratos, favorecería y robustecería las actividades pesqueras en el país, tal y como se señala en el documento:

Entre los bienes del dominio del Estado figuran los derechos de caza y pesca. Estos están reducidos en Costa Rica a la pesca de la tortuga y a la explotación de los bancos perliferos. Ambos rinden ingresos de infima cuantía que no compensan en algunos casos los costos de su recaudación (por lo que) el interés público, lejos de ser protegido por el sistema de concesiones, 
resulta perjudicado en beneficio exclusivo del concesionario, ya que la pesca libre podría dar elementos de vida a un extenso número de individuos pobres o de escasos recursos (ANCR. Congreso, 14674, 1927).

Dos puntos adicionales se otorgaban con la ley de 1927: la imposición del sistema de veda y la intervención de las municipalidades en la autorización de las patentes, cuyas entradas estarían a favor de los gobiernos locales involucrados. Así se cerraba el capítulo de los contratos, al decretar el Congreso: "Art. 1. La pesca de la tortuga y de la concha perla serán industrias de explotación pública, al vencer los contratos o concesiones actuales" (ANCR. Congreso, 14674, 1927).

No obstante, la apertura al libre mercado fue contraria a la preservación de los recursos existentes y amplió la red de extractores, la cual prolongó sus actividades lucrativas y extractivas en el Pacífico en perjuicio del Estado y de las comunidades; a pesar de que las municipalidades tenían poder sobre los tratos y beneficios. Prueba de esto es la secular pobreza que mantuvieron las comunidades costeras de Guanacaste y Puntarenas a lo largo de los siglos XIX y XX.

\section{La persecución del contrabando}

Con respecto al contrabando, puede señalarse que hubo una relación entre los años de auge de la actividad, en la década de 1880, con la persecución del comercio ilegal. También incidieron otros fenómenos como la presencia de más competidores que veían en los contratos privilegios "odiosos"; aspecto que, al parecer, afectaba a los contratistas y al propio Estado. Unos de los primeros denunciantes fueron los hermanos Hidalgo, en 1887: "En Puntarenas se han visto algunas cantidades de sacos conteniendo concha; y se sabe que se han exportado por aquel puerto, no solo la concha, sino algunas porciones de perla" (ANCR, Gobernación, 7179, 1879).

Un ejemplo del problema gestado con el contrabando se denunciaba en el Heraldo de Costa Rica, en enero de 1897, como se aprecia en el siguiente campo pagado: 


\section{Compañia Perlífera Costarricense La Coupañia Perlífera Costarricense, en vista de que, tanto en Puntarenas como en esta Capital, se venden perlas de proceden- cìa fraudulenta, y á las cuales usta tiene derecho, como única explotadora de dicho producto, en la costa del Pacífico de este país, AVISA: \\ que perseguirá ảicho tráfico clandestino $\mathrm{y}$ hará reconocer toda perla cuyo dueñ, no posea los comprobantes de su origen legí- timo, pues la Compañia adjunta á la venta de sus perlasun do- cumento en que constan su peso y calidades. \\ San Jssé, 8 de Enero de 1897. \\ P. P. J. Lorenzo Barreto. \\ Cartago, enero 11 de 1897.}

Fuente: El Heraldo de Costa Rica, 16 de enero de 1897.

La persecución de los pescadores locales fue usual bajo el argumento de tráfico ilegal. Por ejemplo, en una carta de la Comandancia de Puntarenas firmada en julio de 1892, se pide la muestra de concha de perlas que se le decomisó en Las Agujas al señor Carmen Arosemena, con un peso de 6 quintales y 8 libras; y otro poquito que se decomisó en Boquerones, cuyos dueños eran Santos Mojica y Antonio Álvarez Hernández, con un peso de 225 libras. Se procedió a indagar a los testigos del hecho (ANCR. Juzgado Contencioso Administrativo, 5941, 1892). Después de varias deliberaciones se acusó de contrabando de concha perla a los ciudadanos mencionados. Sin embargo, mientras se ejecutaba este caso, se sospechó que los comerciantes establecidos en Puntarenas se apresuraron a exportar la mercadería decomisada, por lo cual, el objeto incautado ya no era una prueba del comercio ilegal existente (ANCR. Juzgado Contencioso Administrativo, 5941, 1892). Finalmente, en marzo de 1896 se falló de la siguiente forma: “Condenase a los procesados Santos Mojica Aguirre y José Antonio Álvarez a perder la concha perla que les ha sido decomisada, cuyo valor será aplicado al Tesoro Nacional y a pagar los daños y perjuicios ocasionados con el delito" (ANCR. Juzgado Contencioso Administrativo, 5941, 1892).

Otro caso de contrabando muy conocido fue el que se llevó a cabo contra los pescadores locales Pablo Sánchez Hurtado, Gregorio Amoretti Guido, Manuel Gómez, Estanislao Montero Ríos y Bonifacio Caballero Contreras, por explotación de yacimientos perlíferos (ANCR. Sala Segunda de Apelaciones, 720, 1903). 
Estos individuos fueron capturados en la costa de la bahía de Santa Elena el 17 de julio de 1902, en el resguardo de La Cruz. Se indica que estaban ocupados en la pesca de la concha perla y se les decomisó lo que tenían. Al parecer pescaban para dos empresas; la primera, propiedad de un nicaragüense, para quien trabajaban los señores Sánchez Hurtado y Amoretti Guido, y la otra, a don Adán Gómez, por lo que se procedió a acusarles de defraudación de la Hacienda Pública.

Sorpresivamente, como respuesta a la demanda, el juez del crimen de Guanacaste dijo que la pesca de perla era libre en los litorales y que los pescadores podían pagar el derecho de matrícula que fijasen las municipalidades de Puntarenas y Liberia. Por lo tanto, no se les podía considerar delincuentes y ordenó que fuesen puestos en libertad. Sobre los productos decomisados, señaló que: "es orden que las embarcaciones pesqueras se reconcentren en Puntarenas" (ANCR. Sala Segunda de Apelaciones, 720, 1903).

En 1907 se presentó otra causa contra un vecino de Golfo Dulce, Francisco Pantoya, por exportación de concha perla sin pagar derechos, en perjuicio de Ezequiel Ríos Deamos. Pantoya había sido el jefe político de Golfo Dulce, y como respuesta a la demanda, el juez declaró que no se había cometido ningún delito: "pues no lo es guardar una mercadería como lo hizo el ex jefe político y que el señor José María Chávez exportó concha por estar autorizado debidamente y haber pagado los derechos del caso" (ANCR. Judicial, 30813, 1907).

\section{Extensión de los territorios concedidos, formas de extracción y veda}

Cuanto más poderoso era el solicitante, más extensa podía ser el área de explotación. En el caso del contrato de Mayer, Mosson y Cañas de 1854, este cubría “todos los golfos y por toda la extensión de la costa perteneciente al territorio de Costa Rica en el océano" (ANCR. Congreso, 7505, 1854). En esta misma dirección, se le cedió a Próspero Fernández, ya que cubría todo el litoral pacífico de la República. El contrato YglesiasLlorente precisaba que el permiso se otorgaba para todas las costas, golfos e islas del Pacífico (ANCR. Gobernación, 7145, 1885).

Es digno de mencionar que la adjudicación de estos privilegios permitía el amplio uso de los terrenos aledaños, que no estuvieran a nombre de propietarios privados. De esta manera, también se podían explotar otros recursos como madera, fibras, peces, cocoteros, entre otros productos.

Los bancos de madreperlas eran abundantes en el siglo XIX, pero las condiciones de extracción agotaron tempranamente estos sitios, a pesar de las vedas y otras medidas para reducir el riesgo de agotamiento. Las áreas más conocidas se localizaron en el interior del golfo de Nicoya, aunque la mayoría de los privilegios otorgados cubrían desde el Golfo Dulce hasta la bahía de Santa Elena. En el interior del golfo de Nicoya, los pescadores partían de San Lucas y se dirigían a otras islas como Manta, Pacero y Tortuga, y al final de la estación lluviosa pescaban en Boquerones. 
Figura 2

BANCOS DE MADREPERLAS EN LA COSTA PACÍFICA DE COSTA RICA 1850-1940

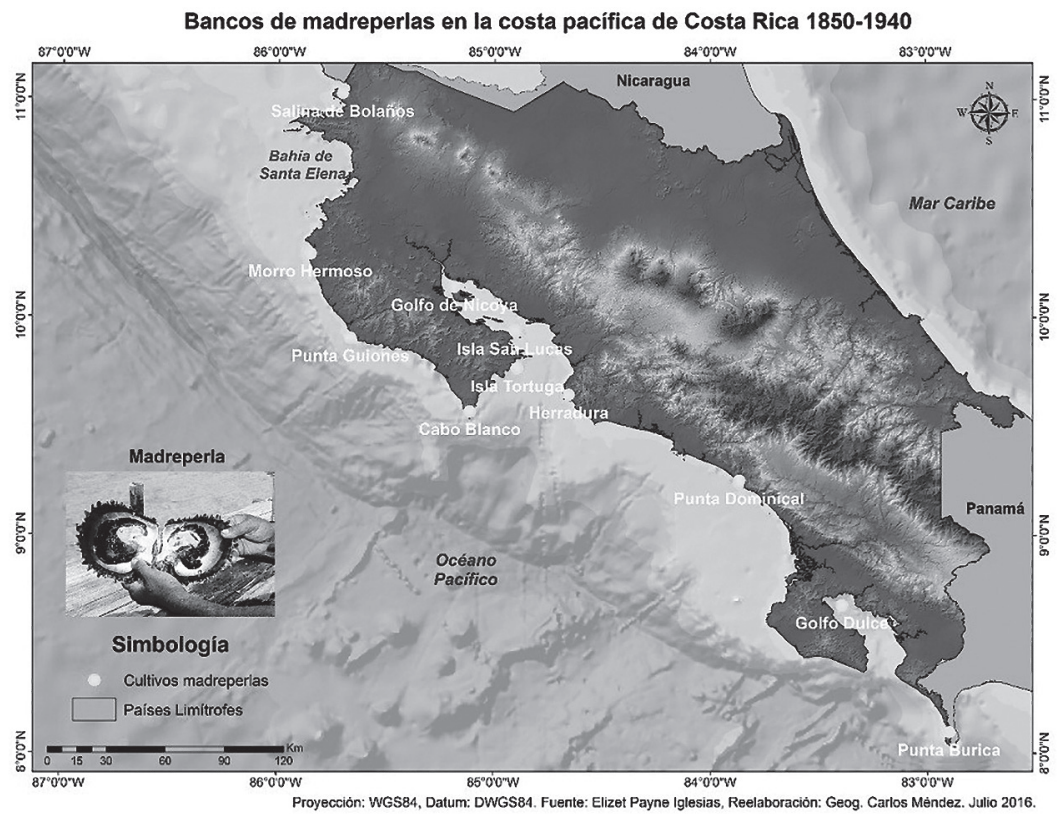

Fuente: Payne Iglesias (2016), reelaboración de Carlos Méndez.

Con ocasión del historial redactado por el señor Romagosa a partir del contrato Amohamad, se puso en tela de juicio la concesión indiscriminada de estos recursos, ya que en opinión del mencionado experto:

Ese contrato dejó un recuerdo muy odioso en Puntarenas. Tenemos concha perla en toda nuestra costa de norte a sur con muy ligeras interrupciones. En el golfo de Nicoya hay concha alrededor de todas las islas, como en San Lucas, en donde la marea seca se ven perfectamente bien en la orilla del lado de Tumba Bote, en las islas del Cedro, en las Tortugas, etc. Y en la banda oriental, en las Agujas, Las Mantas, La Herradura, etc. (ANCR. Congreso, 13069, 1923).

En la Ley de 1927, artículo 4, se delimitaron mejor los placeres de conchas en todo el Pacífico y se señalaron los sitios autorizados:

La explotación de los yacimientos de concha perla, se hará en dos zonas: una de Bahía Salinas a Cabo Blanco y otra de este lugar al Golfo Dulce; y respectivamente para cada zona las municipalidades cabeceras de las provincias de Guanacaste y Puntarenas, podrán establecer patentes industriales cuyo producto será distribuido por partes iguales entre los municipios que integran esas provincias (ANCR. Congreso, 14674, 1927). 
Inmersa en el contexto de la búsqueda de materias primas rentables, la economía del capitalismo incipiente fomentó también la extracción marina, y aunque arrancar la riqueza de los fondos oceánicos no era una actividad nueva ni fácil, pero sí lo fue el uso de maquinaria a gran escala. La primera compañía autorizada en Costa Rica para el empleo de botes de sumersión o submarinos fue la Bayer, Mosson y Cañas en 1854 (ANCR. Congreso, 7505, 1854).

Otra obligación del Estado era velar para que las ostras perlíferas no se agotaran debido a la extracción indiscriminada; al menos así se evidencia en los acuerdos firmados entre las partes; por ejemplo el contrato de Bayer, Mosson y Cañas indicaba, en el artículo 5, que:

La compañía, sus socios o representantes es obligada a conservar y fomentar la cría de la concha de perla aprovechando solamente las conchas grandes y formando nuevos bancos y criaderos de las conchas pequeñas y nuevas, aunque no han llegado a su mayor tamaño o crecimiento (ANCR. Congreso, 7505, 1854).

Poco después, en 1875, Rafael Zaldívar solicitó permiso para traer maquinaria y contratar en el extranjero al personal que la manejara adecuadamente y se comprometiera a preparar mano de obra costarricense. Además de esto, pedía vía libre para construir casas de habitación y caminos. El compromiso era extraer concha perla en gran escala con uno o más vaporcitos, tres buques de vela pequeños, varias lanchas, 45 botes, 40 máquinas completas para bucear, 50 vestidos de refacción, toda la manguera correspondiente y los demás enseres y útiles necesarios (ANCR. Gobernación, 7145, 1885).

La preocupación de los pobladores frente a la extracción masiva y por medio de máquinas provocó la reacción temprana de los habitantes locales, quienes vivían del buceo. En 1879, el cabildo de Puntarenas señaló su preocupación ante el agotamiento de los bancos de ostras, al expresarse de la siguiente forma:

(Informados que) en el golfo de Nicoya están enteramente empobrecidos los bancos de ostras y siendo indispensable vigilar por su importante conservación, con las miras de que se reproduzcan en bien del país en general, se acuerda prohibir por el término de tres años, bajo las multas de veinte y cinco pesos, encareciendo al señor gobernador que se espera de su reconocido celo por el bien público a doble las medidas conducentes que le sugiera su perspicacia para que no se infrinjan estas medidas, habiendo la notoria fianza en los barrios más distantes situados en las playas de dicho golfo y háganse notoria (ANCR, Gobernación, 7179, 1879).

Leída la exposición del señor gobernador en lo referente a la prohibición de pesca de ostras, se acordó comisionar al vicepresidente Saturnino González para que: "con su conocimiento visite e inspeccione los criaderos e informe sobre estos... para 
lo cual se le proporcione embarcación con todos sus anexos y solicite al señor gobernador le auxilie este oficio y ordene este a los jueces que le presten todos los recursos necesarios" (ANCR, Gobernación, 7179, 1879).

En una sesión celebrada el 15 de septiembre de 1879, Saturnino González presentó el informe de la inspección que se le había encargado, en el cual manifiesta que encontró nueve criaderos o bancos de ostras, de los cuales dos se hayan "completamente agotados y los restantes muy empobrecidos o mejor dicho casi desunidos" (ANCR, Gobernación, $7179,1879)$. Agrega que para su recuperación son necesarios "por lo menos 3 años sin que se les toque"; por ello, la municipalidad determina que se cumplan las medidas adoptadas en los acuerdos del 17 de febrero de 1879 (ANCR, Gobernación, 7179, 1879).

Contratos posteriores contemplaban el peligro del agotamiento. Se fijaban las condiciones de pesca considerando el tamaño de la ostra, que fuera madura y no joven o pequeña; y se prohibía el uso de torpedos u otros objetos destructores. Tal y como se suscribió en el contrato Yglesias y Llorente:

Igualmente se compromete Yglesias, a practicar el buceo y pesca sin destruir la cría de la concha perla, sino antes bien conservándola y aumentándola en cuanto fuere posible, como también a no emplear torpedos, ni otros medios destructores, velando por la conservación de los creaderos y bancos perliferos (ANCR. Gobernación, 7145, 1885).

Las actividades de extracción en grandes cantidades en el Pacífico de Panamá hasta 1903 parte de Colombia- eran un asunto que los extractores costarricenses tenían pendiente. Por ejemplo, cuando se aprobó la contrata a favor de Próspero Fernández en 1876, la comisión informó que habían consultado las disposiciones del Congreso de Colombia, acerca de la prohibición de pescar con máquinas en el Archipiélago de las Perlas. Sin embargo, de acuerdo con la información obtenida, se argumentó que la prohibición existente en Colombia, se debía a la explotación de que habían sido objeto esas islas desde siglos anteriores. En cambio, sostenía que las costas de Costa Rica "son vírgenes y no han sido explotadas" (ANCR. Congreso, 8540, 1876); por lo cual se aprobaba la concesión de estos privilegios a Fernández.

De igual forma, se consignaba en el contrato con Demetrio Yglesias y Llorente, en 1885. Este documento expresaba que el arrendatario debería cuidar los bancos y se encargaría de cultivar y explotar la concha perla en los placeres, esteros y demás aguas que comprendían dicha concesión. Pero además, los contratistas se comprometían a explotar en gran escala la madreperla, para lo cual mantendrían embarcaciones de fuerza motriz, lanchas, botes, maquinarias, escafandras y vestidos de refacción. Se obligaban a practicar el buceo con escafandras, sin destruir las crías, antes bien, debían proteger y aumentar los yacimientos: "y se obligan también, bajo pena de caducidad ipso facto de este Contrato, a no emplear torpedos, cartuchos, fuego ni otros medios destructores en la mencionada pesca" (ANCR. Congreso, 013069, 1923). 
La ley emitida durante el gobierno de Ricardo Jiménez Oreamuno en 1927 fue un gran avance en asuntos de pesca en general, puesto que es más precisa respecto al accionar de los involucrados y a los límites de la extracción. Por ejemplo, se estipula la profundidad a la cual se debían sumergir las máquinas, que no debía ser menor de los 11 metros, medidos desde la marea más baja; también limitaba el tamaño de la ostra extraída, que debería ser de no menos de 10 centímetros de diámetro (ANCR. Congreso, 1467,1927$)$.

\section{Las comunidades costeras, el Estado y la defensa legendaria de sus tradiciones}

La documentación consultada ha develado un asunto de sustancial importancia relacionado con la lucha de las comunidades en la defensa de sus tradiciones ancestrales. Las poblaciones de pescadores de concha perla, perla y también de tinte de caracol lucharon con ahínco por la pervivencia de estas actividades. Aunque lamentablemente sobre este tema existe menos información documental, a lo largo del texto es notable la tirantez con la que el Estado, las municipalidades y la élite capitalina manejaban el problema con los pescadores.

En la época colonial, la pesca de perla y madreperla del Pacífico Sur centroamericano estuvo en manos de indígenas y frente a su declive demográfico se recurrió al uso de esclavos negros, particularmente en aquellos parajes como las Islas de las Perlas donde la actividad era importante. En la costa pacífica de Costa Rica y Nicoya, la extracción perlera y con ello, la extracción de tinte de caracol, estuvo a cargo de las comunidades indígenas, pero eran frecuentes las quejas de estos debido a la proliferación en sus sitios de pesca de canoas manejadas por mestizos cuyos dueños eran criollos.

La lucha, sin embargo, no era nueva; la documentación colonial -que no es objeto de este estudio-, prueba en sinnúmero de ocasiones, las quejas que los indígenas de Boruca, Punta Herradura, el golfo de Nicoya y las costas fronterizas con Nicaragua, emitieron en contra de los curas doctrineros, encomenderos, corregidores y pescadores ladinos y blancos debido a la sobreexplotación a la que eran sujetos, no solo a nivel de trabajo, sino de la ocupación de sus territorios ancestrales o patrimoniales.

$\mathrm{Al}$ inicio de la vida independiente y republicana, las quejas persistieron, en particular en la comunidad de Nicoya, en contra de ladinos y pescadores de perlas, concha perla y caracol de tinte. En este último caso, los ladinos entraron en contradicción con los indígenas, quienes insistían en defender sus derechos patrimoniales, como les llamaban.

En 1827, la lucha fue grande y sobresalió el espacio local; los naturales llegaron hasta Cartago a pedir justicia con el fin de que se les otorgase la extracción de tinte como patrimonio de su comunidad. No obstante, las leyes liberales impuestas en el marco de la República Federal Centroamericana hicieron caso omiso a tales solicitudes. La discordia llegó a tal punto que, los funcionarios ladinos que poblaban sitios 
entre Santa Cruz y Nicoya les prohibieron a los indígenas viajar a Cartago, bajo la pena de regresarlos amarrados (ANCR. Gobernación, 8364, 1827).

Otro problema que se devela es la interculturalidad que se presentaba en estas poblaciones, pues en muchas ocasiones los ladinos, mestizos e indígenas eran actores en pugna. En alguna ocasión, los indígenas pudientes se unieron con los ladinos para sacar beneficio a la extracción del caracol (ANCR. Gobernación, 27977, 1843). Es de recordar que, como se ha venido anotando, la explotación del tinte de caracol estaba muy relacionada con la pesca de perlas y de concha.

Así, es de suponer que al abrirse el mercado de los recursos mediante las leyes liberales, el buceo de perlas y la extracción de madreperla, se requiriera de mano de obra ladina, mestiza y mulata. Esta autora ha probado que solo la extracción de caracol de tinte estuvo en manos de los indígenas de Nicoya y Boruca durante el periodo en estudio, aunque no dejaron de existir complicaciones provocadas por las otras poblaciones de la costa que querían ejercer el libre derecho de explotación.

Frente al poder de la élite del Valle Central, la resistencia de ladinos, mestizos e indígenas hizo que el Estado y la municipalidad de Puntarenas tomaran en cuenta la labor de los llamados "buzos de cabeza” y sus familias, quienes vivían de la mencionada actividad. En 1854, los viajeros Wagner y Scherzer refieren que este era el modo de vida de los pobladores de la costa pacífica del país. No eran poblaciones muy grandes y, en el golfo, la mayoría venía de Nicoya -unos 50 pescadores-, según la información de los viajeros mencionados que data de mediados del siglo XIX.

Ya para 1923, el informe de Romagosa señalaba la existencia de unos 500 trabajadores contratados (ANCR. Congreso, 13069, 1923). Aunque el Estado también permitió que las comunidades locales continuaran con la pesca tradicional de perlas y ostras.

Las comunidades de la costa, pobladores dedicados a la extracción de perlas y de tinte de caracol, hicieron valer sus "derechos legendarios" a lo largo de la historia. El gobierno de turno actuó en forma ambivalente respecto a la defensa de estos ciudadanos. Un ejemplo fue el caso del reclamo contra la contrata otorgada a favor del general Próspero Fernández, en la cual los vecinos del Golfo Dulce y Sardinal sostuvieron que desde siempre se habían dedicado a dicha actividad, ante esto solicitaban que, en el tanto Fernández no hubiera comenzado sus labores, les fuese permitida la extracción con buzos de cabeza; la cual era en escasa proporción porque la ejercían casi siempre los pescadores pobres de la costa en forma manual y no afectaba severamente los bancos perleros o de ostras. No obstante, el poder del general fue tal que la petición fue denegada a los pescadores locales, como se evidencia en el siguiente extracto:

Habiéndose concedido privilegio exclusivo al señor general don Próspero Fernández, por decreto legislativo $N^{\circ} 12$ de 30 de mayo próximo pasado, para la pesca de concha de perla en todo el litoral del Pacífico correspondiente a esta República, no ha lugar a la gracia que se solicita (ANCR. Fomento, 639, 1876). 
El conflicto más persistente se presentó con los buzos de cabeza, sobre quienes, para la élite capitalina y los extranjeros, no recaía impuesto alguno. Aunque su situación fue desventajosa frente a los inversionistas que usaban maquinaria, muchas voces los defendieron frente a las autoridades públicas. Aun así, pervivía la idea de que si no pagaban impuestos, sus actividades deberían ser consideradas como delitos. Por ejemplo, esto sucedió en el caso de la explotación que efectuó el inversionista mexicano Pablo Hidalgo, por lo que se expresaba:

Pero volviendo al contrato Hidalgo, tan pronto como entró en vigencia empezaron a perseguir a las pobres gentes de la costa, de tal manera que muchas veces causaba indignación. A cada rato se apresaba a individuos que con mucho sigilo llegaban a las ciudades inmediatas a vender alguna perlita, los juicios que se seguían contra esa gente eran continuos, pero no se podía hacer nada: habia que esperar que el contrato terminara (ANCR. Congreso, 13069, 1923).

Ciertamente, a raíz del contrato Hidalgo, en Puntarenas se formó un comité de defensa que acordó nombrar a los señores Agustín Guido, Juan Suñol y Eduardo de la Guardia para que le pidieran al Gobierno la libre pesca de la concha bajo una reglamentación adecuada; y así lo hizo la administración del licenciado Esquivel. Esto no devino en beneficio de los pescadores y buzos sino que, cancelado el contrato, se declaró libre la explotación de concha perla para nacionales y extranjeros que tuvieran por lo menos 2 años de residencia en el país. Además, se estableció un impuesto de 2 céntimos el kilo para la exportación de concha, la mitad de este monto estaba destinada al Estado y la otra a las municipalidades de Puntarenas y Guanacaste (ANCR. Congreso, 13069, 1923).

Otro contrato considerado de privilegio por los habitantes de la costa fue el suscrito por Federico Tinoco con su primo Guillermo Tinoco y un socio de este, Hermenegildo Cruz. Como se indicó en líneas anteriores, a raíz de la caída del régimen de Tinoco, los vecinos de los pueblos pescadores de ostras solicitaron que los beneficios derivados de los impuestos pasaran a las municipalidades; estas instancias pidieron cancelar el contrato Tinoco y que "se siga explotando dicho negocio mediante un impuesto que será distribuido entre las municipalidades, hospitales y casas de beneficencia de las provincias de Puntarenas y Guanacaste" (ANCR. Congreso, 11741, 1920).

En ese contexto, se estaban declarando nulos los actos del gobierno de Tinoco y los vecinos llegaron a llamarle un monopolio "odioso y exclusivo" (ANCR. Congreso, 11741, 1920). La década de 1920 es clave para comprender la crisis de la actividad. El propio Estado participó al emitir la Ley de pesca de 1927, en la cual liberalizó esta práctica económica, le dio protagonismo a las municipalidades y tomó en cuenta la necesidad de proteger a los pobladores que vivían de esta industria, tal y como se señala: “En cuanto a la pesca de la concha perla, pudiera también declararse con beneficio para 
la comunidad, de libre actividad para los buzos, sin concesiones especiales, facilitando así la vida de la gente de nuestros puertos y costas" (ANCR. Congreso, 14674, 1927).

Además, se manifestaba la defensa de los intereses nacionales frente a los de extranjeros, al señalar: “Tampoco es justo que una compañía extranjera venga a perseguir a nuestras gentes pobres del litoral que en gran parte viven de la industria de la concha perla" (ANCR. Congreso, 13069, 1923).

Los reclamos comunales a menudo eran escuchados en el interior de los poderes locales, de manera que pudieron sacarles algún beneficio; por ejemplo, en 1881, el jefe político de Golfo Dulce solicitó el establecimiento de un impuesto módico sobre la concha de perla que se exportara del litoral de ese cantón, de acuerdo con la tarifa de aduanas vigente (1 centavo por libra), con el fin de fomentar el beneficio público (ANCR. Congreso, 8714, 1881). Otras municipalidades señalaron que las ganancias generadas en las aduanas servirían para la creación de escuelas en los cantones involucrados en estas labores.

\section{Conclusión}

Analizar las políticas públicas en momentos en que el Estado costarricense se estaba consolidando no es tarea fácil. Más en concreto y en relación con tema aquí tratado, los contratos sobre la explotación de la madreperla y perla en el Pacífico de Costa Rica, el papel del Estado a lo largo del siglo XIX e inicios del XX se caracteriza por una política ambivalente y, por ende, contradictoria. En primer término, el Estado, entendido en su proceso histórico, debe ser visto como el intermediario entre lo público y lo privado. No obstante, esta instancia se encontraba en poder de los grupos dominantes que a través de diversos sectores gobernantes fomentaron y manejaron la "cosa pública", casi siempre en su beneficio y desde el Valle Central. Así, visto en un largo plazo, el Estado cede, concede y limita las actividades de los diversos actores sociales o económicos.

No cabe duda de que para la élite asentada en el Valle Central o en el exterior, la explotación de perlas y de concha nácar era un agregado más a sus múltiples inversiones, las cuales se veían consolidadas con la adquisición de tierras, explotación de mangle, maderas preciosas y cocoteros. A esto se sumaba la inversión en edificios, embarcaciones y otros bienes propios del trabajo pesquero.

Estas redes de poder se construyen a lo largo del Estado histórico, se nutren de él. Los contratos sostenidos por Mora a favor de Cañas y sus socios europeos fueron las primeras manifestaciones de la mezcla de losintereses privados con los públicos, en relación con la extracción de la concha nácar y perlas. Posteriormente, les siguieron el general Próspero Fernández, Demetrio Yglesias y Llorente, la familia Tinoco y un sinnúmero de empresarios privados más. Llama la atención que los contratos más prolongados fueron los de Yglesias y Llorente, el mexicano Hidalgo y Guillermo Tinoco, quienes se otorgaron al primero por dieciséis años y a los segundos por veinte años respectivamente. 
En el largo plazo, esta actividad extractiva no fue rentable, lo cual no significa que, por un corto tiempo, no se obtuvieran ganancias importantes. La documentación revela que los bancos de concha se explotaron en demasía. La perla se extrajo desde 1522, pero la concha perla en esa época era desechada, y no fue hasta que en el siglo XIX y principios del XX, cuando los alemanes y japoneses se convirtieron en pioneros en la fabricación de botones de concha perla. Las pequeñas fábricas locales de botones de concha perla quebraron frente al poderoso mercado japonés.

Por su parte, la débil presencia estatal en las poblaciones del Pacífico en el periodo analizado, hizo aún más difíciles las condiciones de vida de los extractores originales o pobladores de la costa que evidentemente no trabajaban para obtener beneficios, sino para subsistir. Los pobladores de las comunidades analizadas llevaron siglos de explotación y de quejas frente a las autoridades; hayan sido estas coloniales, republicanas o liberales. La voracidad de las élites en recursos tan vulnerables revela que optaban por cualquier negocio que pudiera devengar algunos beneficios. Sin embargo, estos no se presentaron y en el Pacífico del país no prosperó ninguna industria perlífera o de madreperla. Menos aún fructificó el tinte de caracol, animal cuyo tinte exige una extracción más sostenible. Aspecto que, como se dijo, será tratado en otro artículo.

En los siglos XIX y XX, las comunidades encontraron diversos medios para hacerse escuchar. En este sentido resulta interesante el recurso a la retórica de la "memoria ancestral" y al "derecho patrimonial" utilizados por ellos. En fin, las comunidades costeras y, en particular, los indígenas de Boruca y Nicoya protestaron por sus derechos consuetudinarios e hicieron uso de sus voces escritas y orales con el fin de que sus peticiones fueran tomadas en cuenta.

Más adelante vinieron las empresas pesqueras de atún y los barcos refrigerados; después el turismo hizo su aparición en esos parajes, se vendieron tierras en enormes cantidades, se abrieron marinas y hoteles. Muchas poblaciones costeras se han quedado sin derecho al agua y han vendido sus parcelas. La mano de obra local, en particular, los jóvenes laboran en el sector servicio de los hoteles y restaurantes. ¿Qué traerá el futuro?

\section{Fuentes primarias manuscritas}

ANCR. Congreso, 10100 (1908).

ANCR. Congreso, 11440 (1919).

ANCR. Congreso, 11741 (1920).

ANCR. Congreso, 13069 (1923).

ANCR. Congreso, 13343 1924).

ANCR. Congreso, 14674 (1927).

ANCR. Congreso, 16064 (1931).

ANCR. Congreso, 16706 (1933). 
ANCR. Congreso, 7505 (1854).

ANCR. Congreso, 8540 (1876).

ANCR. Congreso, 8571 (1875).

ANCR. Congreso, 8714 (1881).

ANCR. Federal, 545 (1825).

ANCR. Fomento, 10332 (1920).

ANCR. Fomento, 5658 (1919).

ANCR. Fomento, 967 (1887).

ANCR. Gobernación, 27977 (1843

ANCR. Gobernación, 428 (1919).

ANCR. Gobernación, 7145 (1885)

ANCR. Gobernación, 7179 (1879).

ANCR. Gobernación, 8364 (1827.

ANCR. Judicial, 30813 (1907).

ANCR. Juzgado Contencioso Administrativo, 5941 (1892).

ANCR. Presidente, 9119 (1853).

ANCR. Sala segunda de apelaciones, 720 (1903).

El Heraldo de Costa Rica. 16 de enero de 1897, año VII, N. 1488.

La Gaceta, 133 (11 de junio de 1927).

\section{Notas}

1 Este trabajo es resultado del proyecto de investigación N. ${ }^{\circ}$ 806-A9-065, titulado “La explotación de perlas en el Pacífico de Costa Rica. 1522-1850", financiado por el CIHAC.

El contrato estipulaba que las diferencias se dirimirían por árbitros nombrados por cada parte o un tercero en caso de discordia quien sería nombrado por el presidente de la Corte Suprema de Justicia. En el artículo X "Queda modificado y refundido en el presente contrato el que se había celebrado con el mismo objeto el 26 de setiembre próximo pasado. Firmado por los diputados el 5 de julio de 1919. Raúl Ugalde (archivero). Firman además Federico y Guillermo Tinoco Gutiérrez. Hermenegildo Cruz.

En agosto de 1913 se informó que los señores Pinel y hermano no tienen permiso para bucear. Se indica que Pinel y hermano no residen en Costa Rica y no han pagado los derechos. ANCR. Fomento, 10332 (1920).

Podrán explotar en las costas e islas hasta 5 kilómetros mar afuera. Cumplirán con las vedas impuestas para la reproducción del molusco (temporadas de celo y reproducción).

Se rechazó la propuesta. Publicado en el diario oficial La Gaceta del 11 de octubre de 1923. Firmaron: Alberto [ilegible], Héctor Esquivel, Juan Murillo, Mariano Fuentes y Manuel Pinel. Arauz, Adams, Abraham Acosta, Juan Suñol, Guier, Barahona, Agustín Guido, E. Arrea, A. Delgado, F. Enríquez, M. Lizano, Guevara, Burgos, Pedro Legares, Macedonio Esquivel, Arturo Salazar.

El señor Runnebaum Benavides tenía en Cartago una fábrica de botones de concha nácar y el señor Gómez Álvarez era un importante exportador de nácar a los Estados Unidos. 
7 La sociedad fue instituida por escritura pública el 23 de junio de 1930 ante el notario Luis Cruz Meza. Entre sus principios señalan: “Uno de los fines, quizá el más primordial y noble en el que descansa la institución que representamos, es el de velar, amparar y fomentar la defensa de nuestras mujeres, el futuro de la patria, cuyas mujeres en su condición social necesitan centros industriales o pequeños talleres para ganarse su vida honrada y dignamente, libres de la empleomanía, sin tener que dejar colgados en el sendero largo y cruel de su vida de lucha, los girones de su virtud: ya ellas se llamen hija, hermana o madre; prestarle toda su ayuda es ennoblecerla y levantarla a un plano superior, mediante el trabajo".

8 La presidenta de la Sociedad era la señora Emilia Calvo Ramírez viuda de Pedro Pérez Zeledón, la secretaria Marina Rodríguez; María Luján Mata de Goyenaga, fungía como vice presidenta y Leonor Espinach de Gutiérrez como vocal.

\section{Bibliografía}

Belaubre, Christopher. "Algunos rasgos biográficos de un comerciante mayorista que participó activamente a la difusión de las luces en Guatemala". Boletín AFEHC (Francia), ficha 719, 2005.

Martínez, Modesto. "Excursión al golfo de Nicoya". Nociones de geografía patria. Ed. Miguel Obregón. San José: Imprenta Nacional. 1921, 156-171.

Meagher, Thomas Francis. “Holidays in Costa Rica, Harper's New Monthly Magazine, 18591860". Tropical Travel. The Representation of Central America in the 19 th Century. Ed. Juan Carlos Vargas. San José: Editorial de la Universidad de Costa Rica, 2008, 255-319.

Molina, Felipe. Bosquejo de la República de Costa Rica, seguido de apuntamientos para su historia. Nueva York: S.W. Benedict, 1851.

Payne Iglesias, Elizet. "La explotación perlífera en Centroamérica y Suramérica: una lectura desde la Historia Ambiental". Poder, economía y relaciones sociales en el Reino de Guatemala. Eds. Carmela Velázquez Bonilla y Elizet Payne Iglesias. San José: Editorial de la Universidad de Costa Rica, 2014, 49-71.

Payne Iglesias, Elizet. "Las perlas de la reina: explotación perlífera en el Pacífico de Centroamérica (1522-1850)". Revista Diálogos. Vol. Especial (2008), 631-654.

Román Trigo, Ana Cecilia. Comercio exterior de Costa Rica, 1883-1930. Tesis de Licenciatura en Historia. Universidad de Costa Rica, 1978.

Solano Astaburuaga, Francisco. "Repúblicas de Centroamérica". Costa Rica en el siglo XIX. Ed. Ricardo Fernández Guardia. San José: EDUCA. 1982, 301-331.

Wagner Moritz y Carl Scherzer. La República de Costa Rica en la América Central. San José: Ministerio de Cultura, Juventud y Deportes. 1974. 
Elizet Payne Iglesias. Hondureña. Doctora en Historia por la Universidad de Costa Rica. Profesora de la Escuela de Historia e investigadora del Centro de Investigaciones Históricas de la América Central (CIHAC) de la Universidad de Costa Rica. Tiene diversas publicaciones sobre la época colonial en Costa Rica, historia de la pesca de perlas y extracción del tinte de caracol en el Pacífico centroamericano, historiografía colonial en Costa Rica, identidad y nación en Honduras, ciudades portuarias en Centroamérica colonial y republicana e historia ambiental. Premio a la Historia Colonial "Silvio Zavala", México, 2008.

Contacto: epaynei@yahoo.com.mx

ORCID: 0000-0001-7739-0666 
